\title{
LIVED IN EXPERIENCE OF WOMEN WITH BREAST CANCER
}

\author{
BLESSY SAMSON, JAYABHARATHI B*
}

Department of Obstetrics and Gynaecology Nursing, SRM College of Nursing, SRM University, Kattankulathur, Kancheepuram, Tamil Nadu, India. Email: jayabharathimariyappan23@gmail.com

Received: 10 August 2016, Revised and Accepted: 24 August 2016

ABSTRACT

Objectives: Breast cancer is a kind of cancer that develops from breast cells. Breast cancer usually starts off in the inner lining of milk ducts or the lobules that supply them with milk. The objectives of the present study are to explore the lived in experience of women with breast cancer and to extrapolate the various dimensions of lived in experience of women with breast cancer.

Methods: This qualitative study was conducted in different units of Metro Hospital and Cancer Institute, Delhi. Phenomenological approach was adopted for the study.The sample consisted of women with breast cancer who fulfilled the inclusion criteria. A total of 15 women with breast cancer were selected using non probability - purposive sampling technique. Structured questionnaire was used to assess the demographic variables of women with breast cancer.An interview schedule with open-ended questions was used to explore the lived in experience of women with breast cancer. The collected data from 15 women with breast cancer were analyzed using Collaizzi's seven - step methodological interpretation approach (analysis framework).

Results: The investigator explored the lived in experience of women with breast cancer by conducting audio taped interview. Various dimensions such as physical dimension, psychological well-being, dealing with stigma, behavioral dimension, immaterial belief, human connectedness, and economical dimension were identified by the investigator. Under each dimension, sub-themes were formulated based on their lived-in experiences.

Conclusion: Nurses working in the different health-care settings have the opportunity to explore the feelings of women with breast cancer and incorporating this knowledge while providing care to strengthen their coping mechanism, improve self-reliance and enhance quality of life.

Keywords: Lived in experience, Women with breast cancer, Various dimensions.

(C) 2016 The Authors. Published by Innovare Academic Sciences Pvt Ltd. This is an open access article under the CC BY license (http://creativecommons. org/licenses/by/4. 0/) DOI: http://dx.doi.org/10.22159/ajpcr.2016.v9s3.14608

\section{INTRODUCTION}

Cancer is a class of diseases characterized by out-of-control cell growth. There are over 100 different types of cancer, and each is classified by the type of cell that is initially affected. Cancer harms the body when altered cells divide uncontrollably to form lumps or masses of tissue called tumors. Tumors can grow and interfere with the digestive, nervous, and circulatory systems, and they can release hormones that alter body function. Tumors that stay in one spot and demonstrate limited growth are generally considered benign. When a tumor successfully spreads to other parts of the body and grows, invading and destroying other healthy tissues, it is said to have metastasized. This process itself is called metastasis, and the result is a serious condition that is very difficult to treat. According to the American Cancer Society, Cancer is the second most common cause of death in the US and accounts for nearly 1 of every 4 deaths. The World Health Organization estimates that, worldwide, there were 14 million new cancer cases and 8.2 million cancer-related deaths in 2012 (their most recent data) [1].

Breast cancer is a kind of cancer that develops from breast cells. Breast cancer usually starts off in the inner lining of milk ducts or the lobules that supply them with milk. A malignant tumor can spread to other parts of the body. A breast cancer that started off in the lobules is known as lobular carcinoma, whereas one that developed from the ducts is called ductal carcinoma [2].

Breast cancer can have a number of symptoms, but the first noticeable symptom is usually a lump or area of thickened breast tissue. There are several different types of breast cancer, which can develop in different parts of the breast. Breast cancer is often divided into non-invasive and invasive types. About one in eight women are diagnosed with breast cancer during their lifetime. There is a good chance of recovery if its detected in its early stages. For this reason, its vital that women check their breasts regularly for any changes. If cancer is detected at an early stage, it can be treated before it spreads to nearby parts of the body. Breast cancer is treated using a combination of surgery, chemotherapy and radiotherapy. Being diagnosed with breast cancer can affect daily life of women in many ways, depending on the stage of breast cancer and type of treatment [3].

The vast majority of breast cancer cases occur in females. Breast cancer is the most common invasive cancer in females worldwide. It accounts for $16 \%$ of all female cancers and $22.9 \%$ of invasive cancers in women. Nearly $18.2 \%$ of all cancer deaths worldwide, including both males and females, are from breast cancer. Breast cancer rates are much higher in developed nations compared to developing ones. There are several reasons for this, with possibly life-expectancy being one of the key factors - breast cancer is more common in elderly women; women in the richest countries live much longer than those in the poorest nations. The different lifestyles and eating habits of females in rich and poor countries are also contributory factors, experts believe. According to the National Cancer Institute, 232,340 female breast cancers and 2,240 male breast cancers are reported in the USA each year, as well as about 39,620 deaths caused by the disease [2].

Breast cancer is the most common cancer among women in Delhi and accounts to about $26.8 \%$. A few decades back, breast cancer was much more common after 50 years of age, and the number of young women suffering from this disease were lesser; almost $65-70 \%$ of patients were above 50 years and only $30-35 \%$ of women were below 50 years of age. However, presently, breast cancer is more common in the younger age group and $50 \%$ of all cases are in the $25-50$ years of age group [4]. 
Williams and Jeanetta conducted a study on lived experiences of women who are breast cancer survivors (BCS). A purposive sampling strategy was used to recruit participants from two Missouri cancer centers. A total of 15 women BCS were interviewed. Three major themes emerged that described the lived experiences of the women. These were factors from the diagnosis and treatment management impacting survivorship, relationship and support system and implication of survivorship. Participants noted that coping with the diagnosis and treatment was a stressful journey and required lots of adjustment and changes. Some developed various techniques such as journaling their activities which provided comfort. In addition, support from family was shared as the key which gave them strength and courage through the different stages of treatment. However, they found it difficult to articulate what survivorship meant. Using in-depth interview techniques, this study shed light on the experiences of women who were diagnosed with breast cancer and have completed treatment. They acknowledged frustration with their diagnosis and body changes. Support received from family and friends helped them cope through their treatment. However, they felt abandoned once the treatment phase was over and were uncertain what survivor hood meant to them [5].

Professional support is an essential element of the illness trajectory. Women need information about preparing for surgery and adjustment to post surgery, cure rates, available treatment options, and treatment cycles. Women also require information on the possible spread of the disease. Information giving is not only an essential objective of cancer care, but is also an important component of the coping strategy that helps women to adjust psychologically to the illness especially after the initial shock of diagnosis [6].

The objectives of this study are to explore the lived in experience of women with breast cancer and to extrapolate the various dimensions of lived in experience of women with breast cancer.

\section{METHODS}

This qualitative study was conducted in different units of Metro Hospital and Cancer Institute, Delhi. It is a 1500 bedded hospital comprising of two tertiary care units namely Metro Heart Institute and Metro Cancer Institute providing comprehensive health care to the patients. Phenomenological approach was adopted for the study. The sample included women with breast cancer who fulfilled the inclusion criteria. 15 women with breast cancer were selected using Non probability - purposive sampling technique. The Inclusion criteria for sample selection includes (a) Women who were between the age group of 20 - 50 years (b) Women with breast cancer diagnosed with in 3 years, (c) Women who were on chemotherapy, and (d) Women who were willing to participate in the study. The exclusion criteria include (a) Women who were medical professionals, (b) Women who underwent surgery for breast cancer, and (c) Women with metastasis.

\section{TOOL FOR DATA COLLECTION}

The tool used for data collection was interview schedule with open ended questions. It consists of 2 sections.

Section A: Structured questionnaire was used to assess the demographic variables of women with breast cancer such as the age, education, occupation, income, religion, type of family, availability of support systems, and duration of disease.

Section B: An interview schedule with open ended questions was used to explore the lived in experience of women with breast cancer.

\section{Ethical consideration}

The proposed study was approved by the dissertation committee of SRM College of Nursing, SRM University, Kattankulathur. Formal permission was obtained from the Management, Metro Hospital and Cancer Institute, Delhi where the study was conducted. Informed consent was obtained from each study participant before the start of data collection. Assurance was given to the subjects that anonymity of each individual would be maintained.

\section{RESULTS}

Audio - taped interviews were listened to and transcribed into verbatim as soon as possible. The collected data from 15 women with breast cancer were analyzed using Collaizzi's seven - step methodological interpretation approach (analysis framework).

Regarding the demographic variables of women with breast cancer, majority $8(53.3 \%)$ of the women with breast cancer were under the age group of 41 - 50 years and only $2(13.3 \%)$ of them were in between the age group of 20-30 years. Regarding education, majority 8 (53.3\%) of them were graduates and only $1(6.6 \%)$ among them had high school education. The data reveals that the majority $9(60 \%)$ of the women with breast cancer were working and 6 (40\%) of them were unemployed and were not salaried. Considering the income of women with breast cancer, $6(40 \%)$ women had family income of more than Rs. 5000/- and only $3(20 \%)$ of them had an income between Rs.1001 - 5001/month. With respect to religion, majority $12(80 \%)$ of women were Hindus, whereas $1(6.6 \%)$ woman was Christian. Regarding the type of family, 11 (73.3\%) of women lived in a nuclear family and remaining $4(26.6 \%)$ lived in a joint family. Considering the availability of support system, $9(60 \%)$ women were supported by their spouse, and only $1(6.66 \%)$ had support from charitable organization. Considering the variable of duration of disease, majority 7 (46.6\%) of them had a duration of disease for 1 year - 2 years and only $2(13.3 \%)$ women had duration of about 6 months.

The analysis revealed that the majority 10 (66.6\%) women had disturbed sleep pattern while $5(33.3 \%)$ had normal sleep pattern. $8(53.3 \%)$ of the women had irregular dietary pattern and 7 (46.6\%) of them had regular dietary pattern. $10(66.6 \%)$ of the women complained of pain and $5(33.3 \%)$ of them had no pain. $10(66.6 \%)$ of the women had inadequate libido and 5 (33.3\%) had adequate libido. All $15(100 \%)$ of them had altered health maintenance (Table 1).

The results depicted that, all the $15(100 \%)$ of the women diagnosed with breast cancer had feelings of worries and fear and all $15(100 \%)$ of them had anxiety (Table 2).

The results revealed that all $15(100 \%)$ of the women diagnosed with breast cancer had feeling of shame regarding their illness. The majority $5(33.3 \%)$ of the women believed that the reason for their illness is due to undisciplined life. All $15(100 \%)$ of the women had previous treatment in the hospital (Table 3).

The analysis revealed that, 12 (80\%) of the women had spells of cry and $3(20 \%)$ of them rarely cried. The majority $9(60 \%)$ of the women did not have anger and $6(40 \%)$ of them had anger either at workplace or with family members (Table 4).

Regarding the immaterial belief, most of the women, 11 (73.3\%) expressed that they had belief in god and $4(26.6 \%)$ did not believe in god. $4(26.6 \%)$ of the women offered special offerings to god and $11(73.3 \%)$ did not offer any thing. $10(66.6 \%)$ of them contemplated and $5(33.3 \%)$ did not contemplate (Table 5).

The results depicts that, $9(60 \%)$ of the women diagnosed with breast cancer had good social relationships and $6(40 \%)$ of them had normal social relationship (nor too good nor too bad). Among all, 5 (33.3\%) of women had the lack of support and remaining 10 (66.6\%) of them had either financial or emotional support from their relatives. 7 (46.6\%) of them were quarrelling either with their spouse or parents and $6(40 \%)$ of them did not quarrel with anybody (Table 6).

The analysis revealed that 5 (33.3\%) of the women had lack of income and $10(66.6 \%)$ had no financial constraints. $8(53.3 \%)$ of them were selffinanced for their treatment and $6(40 \%)$ of them had financial resources 
Table 1: Frequency and percentage distribution of the physical dimension of women with breast cancer (n=15)

\begin{tabular}{|c|c|c|c|c|}
\hline Themes & Sub themes & & Frequency (n) & Percentage distribution (\%) \\
\hline \multirow[t]{3}{*}{ Sleep pattern } & Disturbed & Increased urinary frequency & 6 & 40 \\
\hline & & Preoccupied thinking & 4 & 26.6 \\
\hline & Not disturbed & - & 5 & 33.3 \\
\hline \multirow[t]{3}{*}{ Dietary pattern } & Regular & - & 7 & 46.6 \\
\hline & Irregular & Low income & 3 & 20 \\
\hline & & Lack of interest in food & 5 & 33.3 \\
\hline \multirow[t]{3}{*}{ Pain } & Present & Breast & 4 & 26.6 \\
\hline & & Shoulders & 3 & 20 \\
\hline & Absent & - & 5 & 33.3 \\
\hline \multirow[t]{2}{*}{ Libido } & Adequate & - & 5 & 33.3 \\
\hline & Inadequate & - & 10 & 66.6 \\
\hline \multirow[t]{2}{*}{ Altered health maintenance } & Low grade fever & - & 6 & 40 \\
\hline & Fatigue & - & 5 & 33.3 \\
\hline
\end{tabular}

Table 2: Frequency and percentage distribution of dimension of psychological wellbeing of women with breast cancer $(n=15)$

\begin{tabular}{llll}
\hline Themes & Sub themes & Frequency (n) & $\begin{array}{l}\text { Percentage } \\
\text { distribution (\%) }\end{array}$ \\
\hline $\begin{array}{l}\text { Feelings } \\
\text { of worries }\end{array}$ & Family & 4 & 26.6 \\
& Due to illness & 4 & \\
& Child's future & 7 & 26.6 \\
Fear & Children & 9 & 46.6 \\
Anxiety & Complications & 6 & 60 \\
& Hope of cure & 5 & 40 \\
& Prolonged & 4 & 33.3 \\
& treatment & & 26.6 \\
& Side & 6 & 40 \\
& effects (drugs) & & \\
\hline
\end{tabular}

Table 3: Frequency and percentage distribution of dimension of dealing with stigma among women with breast Cancer $(n=15)$

\begin{tabular}{llll}
\hline Themes & Sub themes & Frequency (n) & $\begin{array}{l}\text { Percentage } \\
\text { distribution (\%) }\end{array}$ \\
\hline Ashamed & $\begin{array}{l}\text { Fear of isolation } \\
\text { Rejection by } \\
\text { family }\end{array}$ & 4 & 26.6 \\
& Hiding the truth & 6 & 33.3 \\
$\begin{array}{l}\text { Reason } \\
\text { for illness }\end{array}$ & Undisciplined life & 5 & 40 \\
& Somebody's & 3 & 33.3 \\
& $\begin{array}{l}\text { curse } \\
\text { Sin }\end{array}$ & 3 & 20 \\
\multirow{2}{*}{$\begin{array}{l}\text { Previous } \\
\text { treatment }\end{array}$} & Inknown hospital & 4 & 20 \\
\hline
\end{tabular}

from their family members and 1 have got final support from NGO's (Table 7).

\section{DISCUSSION}

BCS may experience a mixture of strong feelings, including joy, concern, relief, guilt, and fear. Some people say they appreciate life more after a cancer diagnosis and have gained a greater acceptance of themselves. Others become very anxious about their health and uncertain of how to cope with everyday life. They may feel some stress when frequent visits to the health care team end following treatment. Often, relationships built with the cancer care team provide a sense of security during treatment, and people miss this source of support. This may be especially true as new worries and challenges surface over time, such as any late effects of treatment, emotional challenges including
Table 4: Frequency and percentage distribution of behavioural dimension of women with breast cancer $(n=15)$

\begin{tabular}{llll}
\hline Themes & Sub themes & Frequency (n) & $\begin{array}{l}\text { Percentage } \\
\text { distribution (\%) }\end{array}$ \\
\hline Spells of & Present & & \\
cry & To self & 4 & 26.6 \\
& To others & 8 & 53.3 \\
& Not present & & \\
Anger & - & 3 & 20 \\
& Present & & \\
& Family members & 4 & 26.6 \\
& Workplace & 2 & 13.3 \\
& Absent & & 60 \\
\hline
\end{tabular}

Table 5: Frequency and percentage distribution of immaterial belief of women with breast cancer $(n=15)$

\begin{tabular}{|c|c|c|c|}
\hline Themes & $\begin{array}{l}\text { Sub } \\
\text { themes }\end{array}$ & Frequency (n) & $\begin{array}{l}\text { Percentage } \\
\text { distribution }(\%)\end{array}$ \\
\hline \multirow[t]{2}{*}{ Belief in god } & Present & 11 & 73.3 \\
\hline & Not present & 4 & 26.6 \\
\hline \multirow{2}{*}{$\begin{array}{l}\text { Special } \\
\text { offerings }\end{array}$} & Offered & 4 & 26.6 \\
\hline & $\begin{array}{l}\text { Not offered } \\
\text { anything }\end{array}$ & 11 & 73.3 \\
\hline \multirow[t]{2}{*}{ Contemplation } & Present & 10 & 66.6 \\
\hline & Absent & 5 & 33.3 \\
\hline
\end{tabular}

Table 6: Frequency and percentage distribution of human connectedness of women with breast cancer $(n=15)$

\begin{tabular}{llll}
\hline Themes & Sub themes & Frequency (n) & $\begin{array}{l}\text { Percentage } \\
\text { distribution (\%) }\end{array}$ \\
\hline $\begin{array}{l}\text { Social } \\
\text { relationship }\end{array}$ & Good & 9 & 60 \\
& Normal & 6 & \\
Support from & Financial & 3 & 40 \\
relatives & Support & & 20 \\
& Emotional & 7 & \\
& support & & 46.6 \\
& No support & 5 & 33.3 \\
Quarrelling & With spouse & 3 & 20 \\
& With parents & 4 & 26.6 \\
& No quarrelling & 8 & 53.3 \\
\hline
\end{tabular}

fear of recurrence, sexuality and fertility concerns, and financial and workplace issues. 
Table 7: Frequency and percentage distribution of economical dimension of women with breast cancer $(n=15)$

\begin{tabular}{llll}
\hline Themes & Sub themes & Frequency (n) & $\begin{array}{l}\text { Percentage } \\
\text { distribution (\%) }\end{array}$ \\
\hline $\begin{array}{l}\text { Financial } \\
\text { difficulty }\end{array}$ & Lack of income & 5 & 33.3 \\
& No difficulty & 10 & 66.6 \\
$\begin{array}{l}\text { Financial } \\
\text { resources }\end{array}$ & Self & 8 & 53.3 \\
& Family members & 6 & \\
& NGO's & 1 & 40 \\
\hline
\end{tabular}

Family members and friends may also go through periods of transition. A caregiver plays a very important role in supporting a person diagnosed with cancer, providing physical, emotional, and practical care on a daily or as-needed basis. Many caregivers become focused on providing this support, especially if the treatment period lasts for many months or longer [7].

The investigator explored the lived in experiences of women with breast cancer by conducting audio taped interviews. The investigator identified various dimensions such as physical dimension, psychological well-being, dealing with stigma, behavioral dimension, immaterial belief, human connectedness, and economical dimension. Under each dimension, sub-themes were formulated based on their lived-in experiences.

The study results are consistent with the study carried out by Georgia KB Halkett, on women's experience of making radiation therapy treatment decisions for early breast cancer and to explore how women feel about receiving radiation therapy. An in-depth understanding of the women's experience was developed using a qualitative research approach underpinned by hermeneutic phenomenology. In-depth interviews were conducted with 18 women who had completed treatment for early breast cancer. The themes that emerged from the data were: Being challenged, getting ready, beyond control, regaining a sense of control and getting through it. This study provides health professionals with an initial understanding of the women's perspective of the experience of making radiation therapy treatment decisions for early breast cancer. This study concludes by suggesting that further research needs to be conducted to gain an understanding of how other patients feel about treatment decision-making and radiation therapy [8].

The study results are consistent with the study done by Kimlin Tam Ashing-Giwa conducted a qualitative study with BCS of various ethnicities. A total of 102 BCS participated in focus group interviews (24 African Americans, 34 Asians, 26 Latinas and 18 Caucasians); 20 health professionals participated in key informant interviews. Important ethnic differences in type of treatment were noted, Asians and Latinas were more likely to receive mastectomies and African American BCS were least likely to receive adjuvant therapies, including radiation and chemotherapy. These BCS enjoyed a fairly good overall health-related quality of life with some persistent concerns. The prevailing concerns among all women included overall health, moderate physical concerns, cancer recurrence or metastases, psychosocial concerns related to worry about children and burdening the family, and body image and sexual health concerns. Additional challenges included: Lack of knowledge about breast cancer; medical care issues such as insurance, cost and amount of time spent with physician; cultural sensitivity of providers, language barriers, cultural factors related to beliefs about illness, gender role and family obligations (e.g. selfsacrifice). These BCS, particularly the women of color, voiced that their spiritual beliefs and practices are central to their coping. The results of this investigation will provide preliminary information to survivors and health-care providers about the impact of culture and socio-ecological contexts on survivorship [9].
In the current study, the investigator identified that under the physical dimension, sleep disturbances, irregular dietary pattern, pain, decreased libido, and altered health maintenance were identified as the major stressors for the women. With regard to dimension of psychological well-being, feelings of worries, fear and anxiety were present among women with breast cancer. Under the dimension of dealing with stigma, the common problems reported by the study sample were feeling ashamed, their reason for illness and previous treatment were mentioned. Behavioral factors such as spells of cry and angry were identified as the stressors for the women. Related to dimension of immaterial belief, the investigator identified sub themes like belief in god, had no special offerings to god but used to conduct prayers. Related to human connectedness, the investigator identified sub themes such as good social relationship and was getting emotional support from relatives and no quarrelling with anyone as the major stressors. With regard to economical dimension, they did not had financial difficulty and reliance on self and spouse for financial support.

The study results are consistent with the study done by Cebeci et al. (2012) conducted a study among eight women with ongoing breast cancer chemotherapy treatment, which occurred in an ambulatory unit. The data were collected using semi-structured and in-depth individual interviews. All interviews were tape-recorded, and the results were obtained by analyzing the content of the recorded data. Three major themes related to the experiences of women living with breast cancer were identified. They are as follows: (1) needs (the need for spouse and family support, the need to worship, and the need to receive and share information), (2) living with losses (loss of the breast and of one's hair), and (3) changes (changes in one's normal life, change in self-perception, changes in the perception of the value of health, and a greater appreciation for life). This study was conducted to increase awareness concerning women's perceptions of their care and various needs during breast cancer treatment. The results of this study challenge health-care providers and educators to be more aware of the difficulties that women face when living with breast cancer [10].

\section{CONCLUSION}

The present study explored the lived in experiences of women with breast cancer which was found to be unique and the various factors that influenced their daily living. The investigator identified various dimensions such as physical dimension, psychological wellbeing, dealing with stigma, behavioral dimension, immaterial belief, human connectedness, and economical dimension. Nurses working in the different health-care settings have the opportunity to explore the feelings of women with breast cancer and incorporating this knowledge while providing care to strengthen their coping mechanisms, improve self-reliance and enhance quality of life.

\section{REFERENCES}

1. Cancer: Facts, Causes, Symptoms and Research - Medical News Today. Available from: http://www.medicalnewstoday.com/info/canceroncology.

2. Breast Cancer: Causes, Symptoms and Treatments. Available from: http://www.medicalnewstoday.com/articles/37136.php.

3. Breast Cancer. Available from: http://www.nhs.uk/.../Cancer-of-thebreast.../Symptoms.asp.

4. Statistics of Breast Cancer in India. Available from: http://www. breastcancerindia.net/statistics/stat_delhi.html.

5. Williams F, Jeanetta SC. Lived experiences of breast cancer survivors after diagnosis, treatment and beyond: Qualitative study. Health Expect 2016;19(3):631-42.

6. The Experience of Living with Breast Cancer. Available from: http://www.citeseerx.ist.psu.edu/viewdoc/ download?doi=10.1.1.542.6676\&rep=rep1.

7. Breast Cancer: Coping with Side Effects. Types of Cancer, Breast Cancer. Available from: http://www.cancer.net.

8. Halkett GK, Arbon P, Scutter SD, Borg M. The breast cancer patient's 
experience of making radiation therapy treatment decisions. The Radiographer 2005;52(1):17-21.

9. Ashing-Giwa KT, Padilla G, Tejero J, Kraemer J, Wright K, Coscarelli A, et al. Understanding the breast cancer experience of women: A qualitative study of African American, Asian
American, Latina and Caucasian cancer survivors. Psychooncology 2004;13(6):408-28

10. Cebeci F, Yangin HB, Tekeli A. Life experiences of women with breast cancer in south western Turkey: A qualitative study. Eur J Oncol Nurs 2012;16(4):406-12. 